EXPERIMENTAL STUDY

\title{
In vitro basal and GnRH-stimulated secretion of gonadotrophins reflects long-lasting modulatory effects, and peripheral levels are not predicted by pituitary responsiveness to GnRH
}

\author{
J J Evans and S Janmohamed \\ Division of Endocrinology and Metabolism, Hammersmith Hospital, London, UK and Department of Obstetrics and Gynaecology, Christchurch School \\ of Medicine, Christchurch, New Zealand \\ (Correspondence should be addressed to J J Evans, University Department of Obstetrics and Gynaecology, Christchurch Women's Hospital, \\ Private Bag 4711, Christchurch, New Zealand; Email: john.evans@chmeds.ac.nz) \\ (S Janmohamed is now at Department of Endocrinology, St Bartholomew's Hospital, London, UK)
}

\begin{abstract}
Objective: Production of the appropriate pattern of gonadotrophin levels is crucial to proper functioning of the female reproductive system. We aimed to establish whether the pituitary has invariant secretory characteristics when isolated from in vivo controls. We aimed to obtain information during both the rising and declining phases of the gonadotrophin surge.

Design: This study investigated factors that are directed at the pituitary by isolating it from the acute influences of the in vivo environment and studying gonadotrophin secretion in vitro.

Methods: Pituitaries of adult female rats were collected at selected times during the day of pro-oestrus and incubated in vitro, and at the same time blood was collected. Peripheral levels of LH and FSH were measured over the whole day of pro-oestrus, basal in vitro secretions of LH and FSH from pituitaries were measured, GnRH-stimulated LH and FSH secretion were assessed, and the responsiveness of LH and FSH secretion to GnRH were calculated.

Results: Peripheral levels of LH peaked at $1800 \mathrm{~h}(P<0.02)$ followed by a subsequent decline. In contrast, although FSH had a peak at $1800 \mathrm{~h}(P<0.01)$, serum levels were also high at the end prooestrus. The profile of basal LH and FSH secretion from the pituitary in vitro, in the absence of added secretagogue, resembled that of the peripheral blood levels of each gonadotrophin. Pituitaries collected at $1800 \mathrm{~h}$ secreted most LH $(P<0.02)$. FSH secretion was low early on the day of pro-oestrus and then increased to and was maintained at high levels in the last quarter of the day $(P<0.01)$.

When the pituitaries were stimulated with GnRH the patterns of LH release and FSH release approximated those observed for basal release. Responsiveness of the pituitaries to GnRH was calculated by determining the ratio of GnRH-stimulated release to basal release. However, low levels of gonadotrophin were secreted even from pituitaries which were highly responsive as determined from consideration of percentage increase in secretion induced by GnRH.

Conclusions: The secretory activity was dependent on the time of day the pituitaries were collected. Since the secretion occurred after the tissue had been removed from the direct influence of the in vivo environment, the variations in secretion must reflect long-lasting components of the mechanism that regulate gonadotrophin concentrations. There were changes in both LH and FSH responsiveness to GnRH stimulation over the day of pro-oestrus. Delineation of the time courses and changing predominance of multiple processes is needed to assist understanding the mechanisms underlying the female reproductive cycle.
\end{abstract}

European Journal of Endocrinology 141 512-520

\section{Introduction}

Circulating gonadotrophins are vital endocrine regulators of ovarian function. Follicles mature under the influence of follicle-stimulating hormone (FSH), and luteinising hormone (LH) provides the primary pituitary signal for ovulation. The profiles of LH and FSH in the blood of rats during the 4 day oestrous cycle and on the day of pro-oestrus are well established (1-3). Coincident preovulatory peaks of the two gonadotrophins occur on the evening of pro-oestrus, followed by a decline in LH levels while FSH secretion remains high during late 
pro-oestrus and early oestrus. Of less certainty is the relationship of peripheral levels to the changing cyclic behaviour of the pituitary gland. The levels of gonadotrophins are the result of a complex of signalling systems operating at the level of the anterior pituitary gland. Thus, the pituitary receives stimulatory signals from gonadotrophin-releasing hormone $(\mathrm{GnRH})(4,5)$, the primary hypothalamic LH/FSH-regulating peptide, as well as other peptides (6). The response to these signals is modulated by other factors, including ovarian steroids (7-9), inhibin, activin and follistatin (10-12). It is also known that under some circumstances $\mathrm{GnRH}$ will desensitise the pituitary and further exposure to GnRH will not be efficient in inducing gonadotrophin release (13-15). However the relevance of these factors to the LH and FSH patterns that are produced remains uncertain because there are still only sparse data on the time-dependent behaviour of the pituitary related to the progress of pro-oestrus.

When GnRH is administered to rats at a selected time during a day of the oestrous cycle, $\mathrm{LH}$ and FSH rise to an extent that is dependent on the stage of the cycle (1618 ). In addition to that variation, there also is a timedependent response of $\mathrm{LH}$ and FSH during the day of pro-oestrus (19). However, studies on the in vivo responses of the pituitary to GnRH have invariably been restricted to a limited number of time points. Therefore details of pituitary behaviour around and following the pro-oestrous gonadotrophin surge have remained unclear. Additionally, such studies are problematic since it is virtually impossible to control for all in vivo factors that can modulate the responses during the course of the study. In vitro studies have also demonstrated a change in response up to the time of the $\mathrm{LH}$ surge (20), but effects during the declining phase of the surge were not examined. Therefore, although alterations in responsiveness during the oestrous cycle and the day of pro-oestrus have been observed, the full details remain uncertain.

The present study provides information related to gonadotroph behaviour. First, an in vitro protocol was used to isolate pituitary tissue from multiple and changing in vivo factors. Secondly, the in vitro basal release of $\mathrm{LH}$ and $\mathrm{FSH}$ was examined at frequent intervals during the whole day of pro-oestrus, including after the gonadotrophin surge. Thirdly, responsiveness to GnRH was concurrently assessed by measuring gonadotrophin output after GnRH stimulation. Thus basal release, GnRH-stimulated release and circulating gonadotrophin levels were measured in parallel and directly compared. Also, differences in behaviour between LH and FSH were noted during pro-oestrus.

\section{Methods}

Adult female Wistar rats were housed in controlled lighting conditions, $14 \mathrm{~h}$ light: $10 \mathrm{~h}$ darkness, lights on at $0500 \mathrm{~h}$, off at $1900 \mathrm{~h}$. The oestrous stage of the rats was monitored by daily vaginal smears. Rats which had at least three 4-day oestrous cycles were used in this study. On the day of pro-oestrus, the rats were killed by exposure to a rising concentration of $\mathrm{CO}_{2}$ gas and blood was collected by cardiac puncture. The serum was separated and stored at $-20{ }^{\circ} \mathrm{C}$ until assayed by RIA for $\mathrm{LH}$ and FSH. The pituitary gland was collected and the posterior pituitary was discarded. Each anterior pituitary was halved and the two halves were transferred to $1000 \mu \mathrm{l}$ prewarmed incubation medium in culture wells of a 24-well plate using standard methodology $(21,22)$. The incubation medium consisted of medium 199 with Hanks' salts, containing $1.4 \mathrm{~g} \mathrm{NaHCO}_{3} / \mathrm{l}, 5.95 \mathrm{~g} \mathrm{HEPES} /$ $\mathrm{l}$ and $1 \mathrm{~g} \mathrm{BSA} / \mathrm{l}$.

Incubations were carried out at $37^{\circ} \mathrm{C}$ in $5 \% \mathrm{CO}_{2}$ and $95 \%$ air. After 30 min the medium was changed to fresh medium in each well, followed by a $120 \mathrm{~min}$ preincubation settling period, a time chosen following preliminary studies. The medium was changed after $60 \mathrm{~min}$. Basal secretion of $\mathrm{LH}$ and FSH into fresh medium over a $60 \mathrm{~min}$ period was then evaluated. The medium was replaced and pituitaries were then exposed to $1 \mathrm{nmol} / \mathrm{l}$ $\mathrm{GnRH}$ for $60 \mathrm{~min}$, and again the medium was collected, to determine $\mathrm{GnRH}$-stimulated release. Medium was stored at $-20{ }^{\circ} \mathrm{C}$ until assayed.

Blood and pituitaries were collected at 11 time points on the day of pro-oestrus; five or six rats were examined at each time. Two time points were in the morning dark phase $(0000 \mathrm{~h}, 0400 \mathrm{~h})$, eight were in the light phase $(0800 \mathrm{~h}-1800 \mathrm{~h})$ and three were in the evening dark phase $(2000 \mathrm{~h}-2400 \mathrm{~h})$. Basal pituitary secretion was evaluated at all time points, and GnRH-stimulated secretion was determined at all time points from $0800 \mathrm{~h}$, after the morning dark phase. Serum was collected at all time points.

Radioimmunoassays for $\mathrm{LH}$ and $\mathrm{FSH}$ were performed using standard methods and reagents generously supplied by the National Hormone Pituitary Program of the National Institute of Diabetes and Digestive and Kidney Diseases and Dr A F Parlow, in a double antibody protocol. The results were calculated using NIDDK standard preparations as reference.

For statistical evaluation of differences in secretory activities at stages of the day of pro-oestrus, a range of time points was sometimes employed. In these cases, the individual levels or values were used in the analysis. Resulting $P$ values are detailed in the text together with the groups that were used in the analysis. Graphs depict the separate groups. One way analysis of variance (ANOVA) was used to determine differences between groups; $P<0.05$ was taken to indicate a significant difference between groups.

\section{Results}

The profile of mean LH levels in peripheral serum over the day of pro-oestrus showed a surge which peaked at $1800 \mathrm{~h}$ ( $P<0.01 ; 1800 \mathrm{~h}$ vs $1000-1200 \mathrm{~h})$. Levels rose 


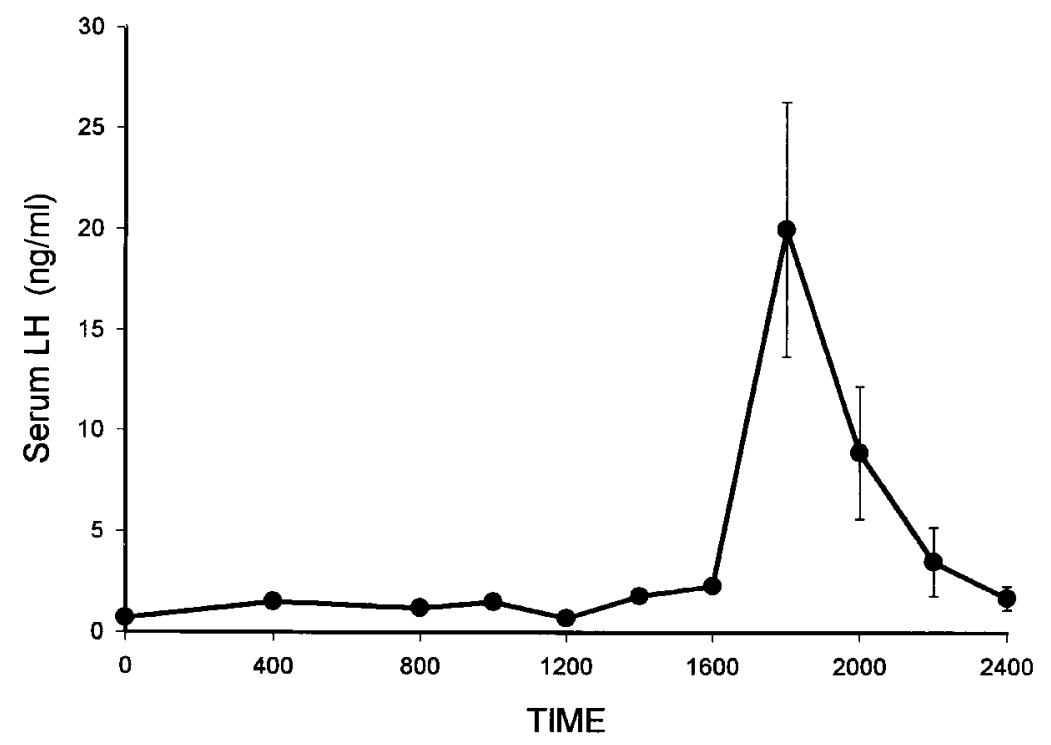

Figure 1 The levels of $\mathrm{LH}$ in serum of female rats at selected times during the day of pro-oestrus. A surge on the evening of pro-oestrus was observed. The means and S.E.M. are depicted. rapidly and then declined to be low again by the end of the day (Fig. 1).

The pattern of release of $\mathrm{LH}$ from pituitaries incubated in the absence of any added peptide revealed a peak of secretion from tissue collected at $1800 \mathrm{~h}$ (Fig. 2) $(P<0.02 ; 1800 \mathrm{~h}$ vs $1000-1200 \mathrm{~h})$. Thus the pituitaries had activity which had been incorporated in vivo into their secretory processes, and which influenced secretion in vitro without the presence of further secretagogue. The basal secretory activity changed over the day of pro-oestrus to produce the pattern observed. Thus basal secretion from the pituitary was dependent on the time of day that the tissue was removed from the in vivo environment.

The pituitaries which were all stimulated with the same concentration of GnRH secreted LH in a pattern whereby those collected at $1800 \mathrm{~h}$ secreted more LH in response to $\mathrm{GnRH}$ than pituitaries collected at any other time $(P<0.01 ; 1800 \mathrm{~h}$ vs $1000-1200 \mathrm{~h})$. Pituitaries collected after this time were found to have less secretory activity (Fig. 3).

Using these data, the percentage increase in $\mathrm{LH}$ response to GnRH (i.e. GnRH-stimulated secretion/basal secretion) was calculated at each time point, and the resulting ratio plotted. The ratio of stimulated LH secretion to basal LH secretion changed during the day of pro-oestrus. The increase began at $1600 \mathrm{~h}$ and exceeded values present earlier in pro-oestrus. Responsiveness remained high until the end of the day of prooestrus $(P<0.01$; 1600-2400h vs 0800-1400 h). Thus the pituitary was more sensitive to $\mathrm{GnRH}$ at the end of pro-oestrus than at the beginning (Fig. 4).

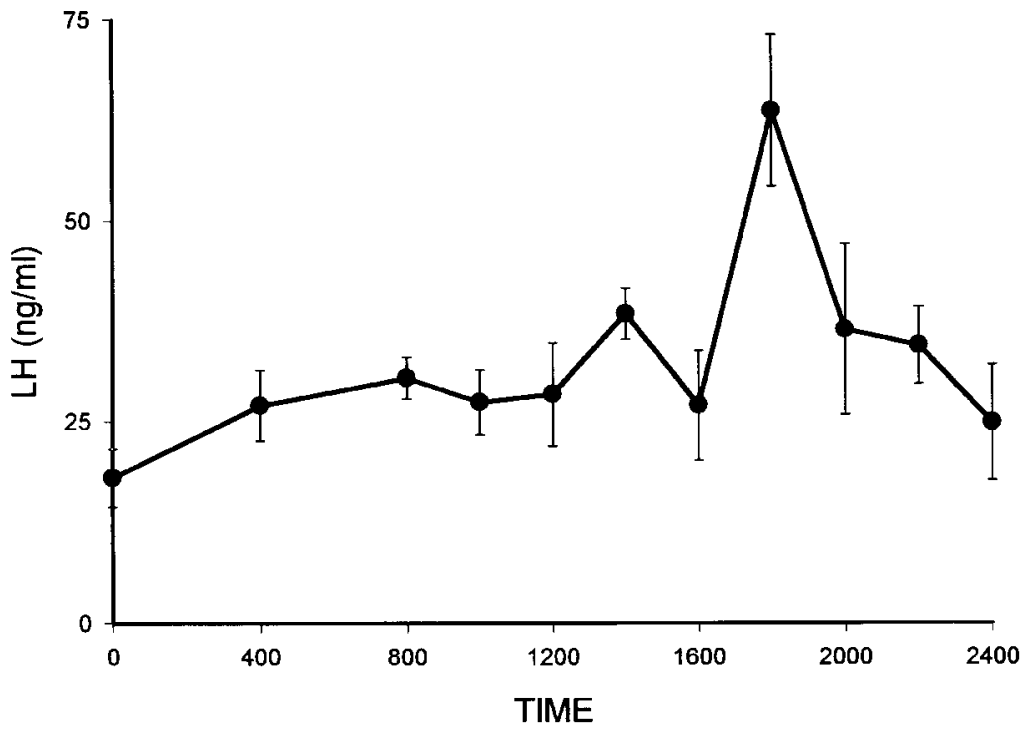

Figure 2 The levels of $\mathrm{LH}$ released from two hemipituitaries of female rats in vitro during a $1 \mathrm{~h}$ incubation. The pituitaries were collected from the rats at the times indicated on the day of prooestrus. Basal secretion of $\mathrm{LH}$ varied during the day, and a peak of secretion was observed in the evening. The means and S.E.M. are depicted. 
Figure 3 The levels of $\mathrm{LH}$ released from two hemipituitaries of female rats in vitro during a $1 \mathrm{~h}$ incubation in the presence of $1 \mathrm{nM} \mathrm{GnRH}$. The pituitaries were collected from the rats at the times indicated on the day of pro-oestrus. The means and S.E.M. are depicted.

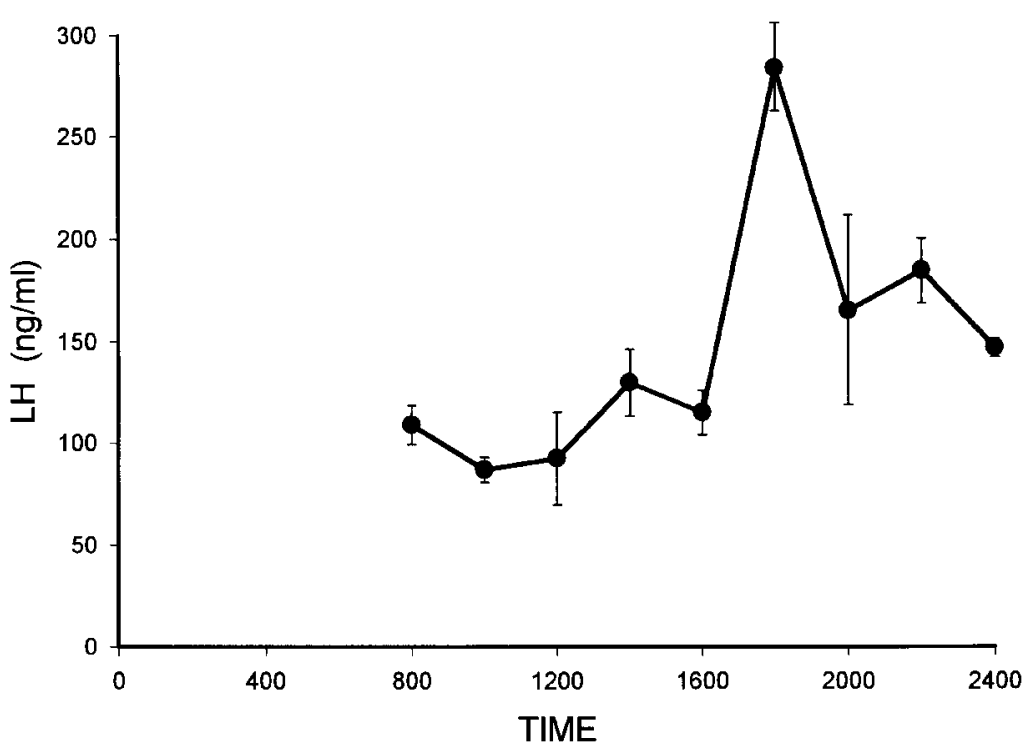

The profile of FSH levels in serum was somewhat different from that for LH. There was again a rise in the evening of pro-oestrus at $1800 \mathrm{~h}(P<0.01 ; 1800 \mathrm{~h}$ vs $1000-1200 \mathrm{~h}$ ) but the FSH level did not then return to baseline levels, but rather another peak developed. Thus, at the end of the day of pro-oestrus there were high levels of FSH in serum (Fig. 5).

The profile of the basal in vitro FSH secretion had an overall similarity to that of serum FSH levels; namely, low levels early in the day followed by a rise and continued high levels in the last quarter of the day (Fig. 6) $(P<0.01 ; 1800-2400 \mathrm{~h}$ vs $0800-1200 \mathrm{~h})$.

When the pituitaries were stimulated with GnRH the pattern of FSH release in vitro was similar to that observed for basal release (Fig. 7); again there was more FSH secreted later in the day $(P<0.01 ; 1800-2400 \mathrm{~h}$ vs 0800-1200 h).

When the FSH responsiveness of the pituitaries (GnRH-stimulated secretion/basal secretion) was calculated, it was found that the variations in the ratios and S.E.M. values were relatively large (Fig. 8). This suggested that in individual rats FSH responsiveness was not tightly tied to the time of day.

\section{Discussion}

The relationship between the events at the level of the pituitary and concentrations of LH and FSH that are
Figure 4 The responsiveness of LH secretion, to $\mathrm{GnRH}$, from hemipituitaries of female rats in vitro. The tissue was incubated in control medium and then in the presence of $1 \mathrm{nM} \mathrm{GnRH}$; the ratio of $\mathrm{GnRH}$-stimulated $\mathrm{LH}$ release to basal $\mathrm{LH}$ release was calculated. The pituitaries were collected from the rats at the times indicated on the day of pro-oestrus. Responsiveness was higher towards the end of the day than at the beginning. The means and S.E.M. are depicted.

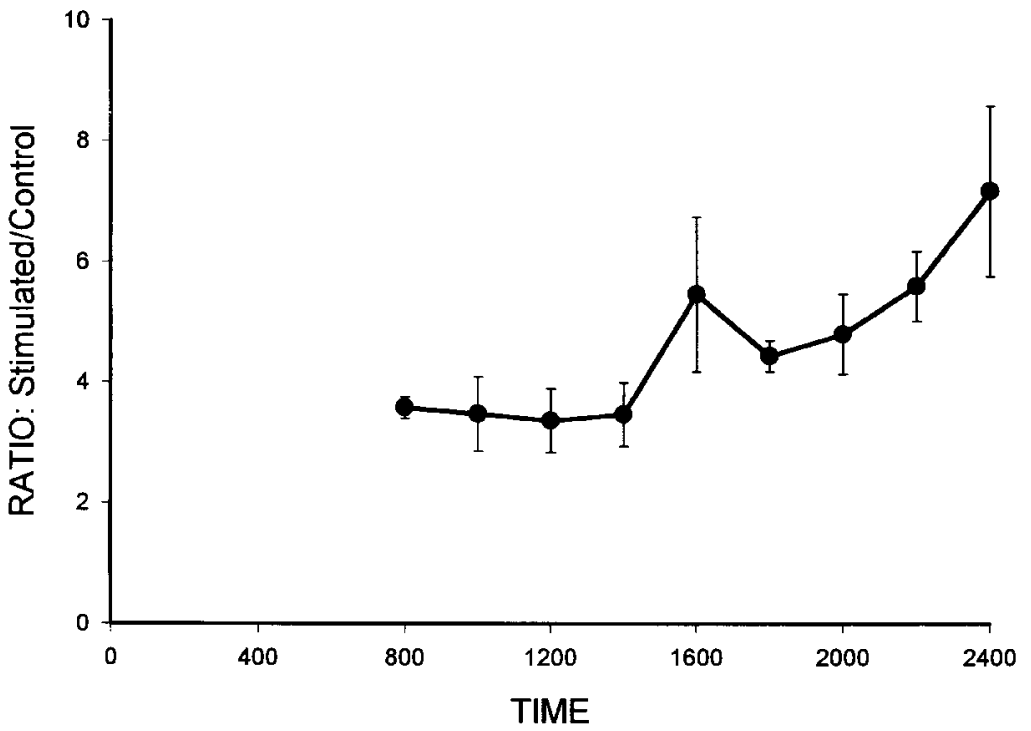




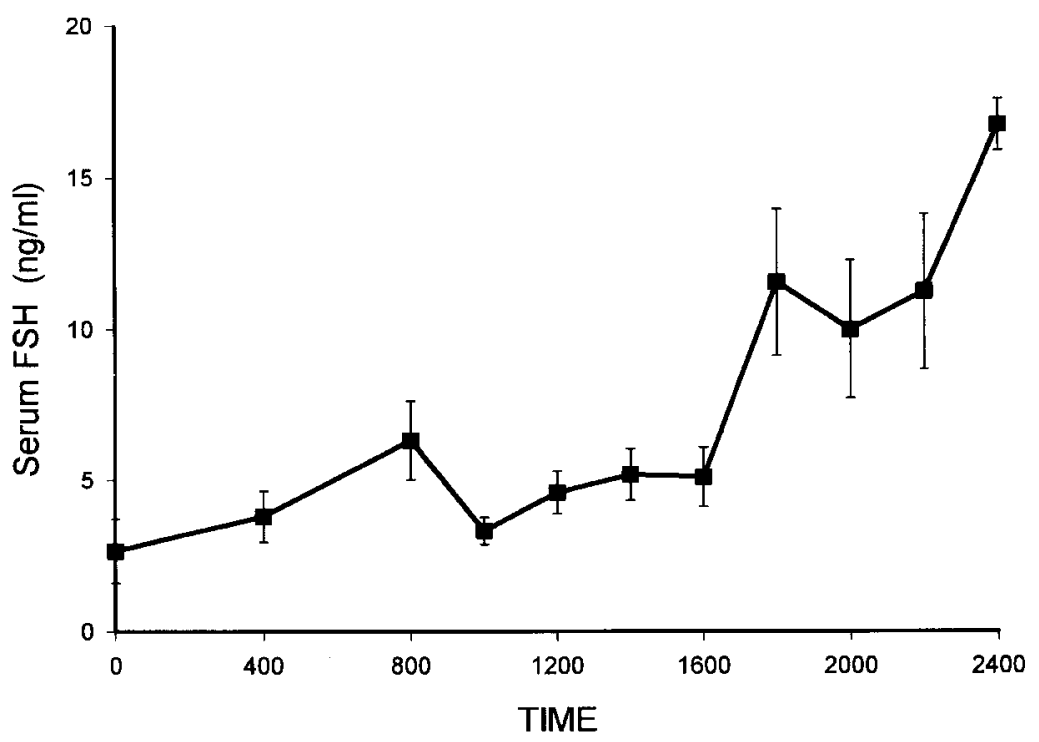

Figure 5 The levels of FSH in serum of female rats at selected times during the day of prooestrus. There was a rise in FSH levels in the evening of pro-oestrus, and the levels remained high to the end of the day. The means and S.E.M. are depicted. delivered to the ovary is a topic central to understanding reproductive function. The regulation of $\mathrm{LH}$ and that of FSH are at least partly distinct, and the peptides, including GnRH, which impinge on the pituitary seem to differentially affect LH and FSH (23-25). It is clear that a complex series of interrelated processes is involved in producing the peripheral profiles of FSH and LH. A number of these processes will be centred on the pituitary itself, and will vary with time in their effects on the dynamic, cyclic system. This study revealed timedependent characteristics of secretion of gonadotrophins from the pituitary over the day of pro-oestrus.

Firstly, our study established a variation in basal secretion of LH from the pituitary when it is isolated from the hypothalamus at different times of the day. Basal release had a temporal pattern similar to that for peripheral LH levels. GnRH increases have been observed in the portal blood in parallel with peripheral $\mathrm{LH}(26,27)$ and it is believed that increased $\mathrm{GnRH}$ secretion is the important factor in eliciting the $\mathrm{LH}$ surge (28). In the present study, GnRH-stimulated release from the pituitary in vitro followed a similar pattern to basal release.

However, the in vitro incubation results did not exactly replicate the in vivo serum patterns that were concurrently determined in this study. The peak of in vitro secretion was proportionately less raised than the surge of serum levels. Factors present in vivo, such as GnRH self-priming (29-31), and other sensitising peptides, which include oxytocin $(22,32)$ and neuropeptide $\mathrm{Y}(33,34)$, could account for the enhanced in vivo secretory activity as reflected by the serum

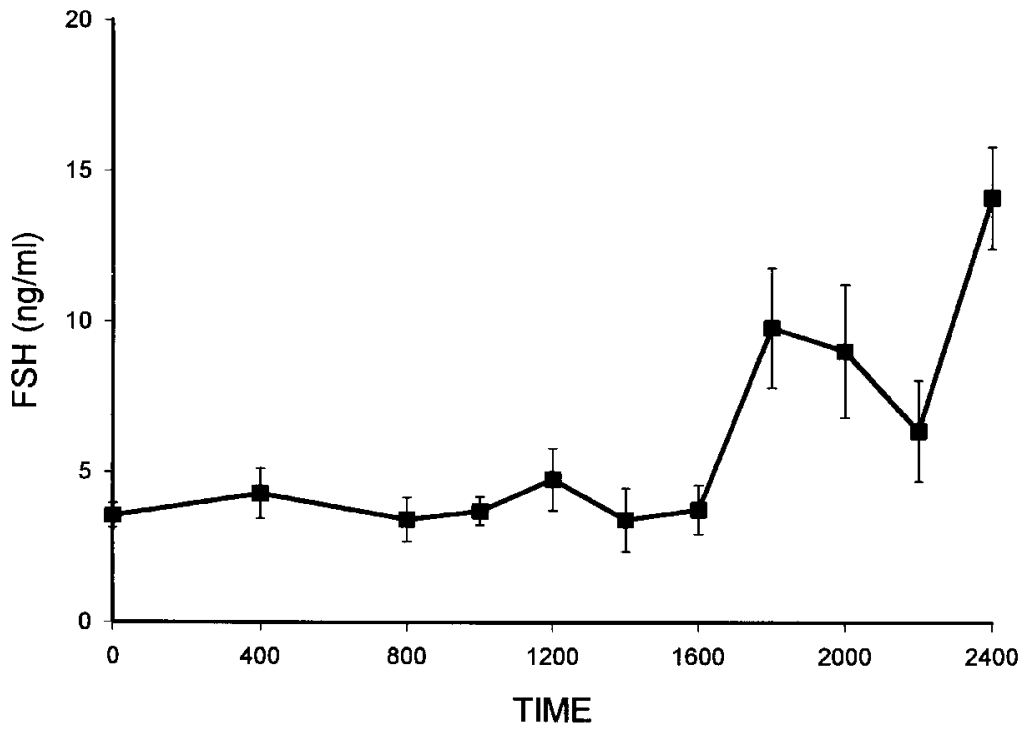

Figure 6 The levels of FSH released from two hemipituitaries of female rats in vitro during a $1 \mathrm{~h}$ incubation. The pituitaries were collected from the rats at the times indicated on the day of prooestrus. Basal secretion in vitro of FSH had a pattern similar to that of peripheral concentrations. The means and S.E.M. are depicted. 


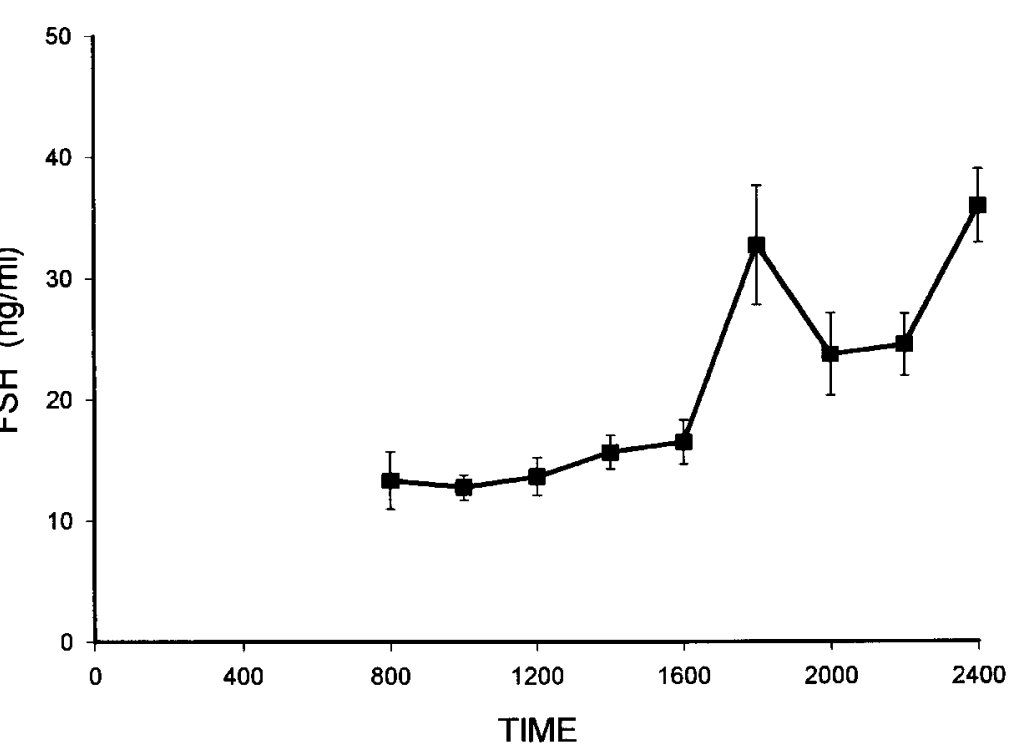

Figure 7 The levels of FSH released from two hemipituitaries of female rats in vitro during a $1 \mathrm{~h}$ incubation in the presence of $1 \mathrm{nM} \mathrm{GnRH}$. The pituitaries were collected from the rats at the times indicated on the day of pro-oestrus. The means and S.E.M. are depicted.

profile. These other influences were deliberately removed by using an in vitro protocol to study pituitary secretion. In this regard, our results were slightly different from those obtained in an earlier study using $2 \mathrm{~h}$ incubations, where a peak of LH secretion was not

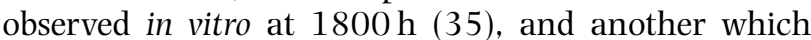
found a poor relationship between serum LH levels and basal secretion (36). It seems, therefore, that our protocol was more effective in providing an in vitro means of examining in vivo events.

The increase in LH serum levels in the evening of prooestrus may have resulted from a number of mechanisms other than a primary change in GnRH levels. Another possibility is that the increased secretion might have occurred via an increase in sensitivity of the pituitary to a given amount of GnRH. Indeed we found that there was varied responsiveness during the day of pro-oestrus. However, the change in sensitivity did not follow the same pattern as either the levels of LH in the serum or LH secretion in vitro. During the day, the LH sensitivity of the pituitary to GnRH increased and remained elevated relative to the early times of prooestrus. Hence, it was notable that GnRH-stimulated secretion, using a constant concentration of GnRH, fell after $1800 \mathrm{~h}$. This was in spite of the responsiveness index of the pituitary remaining high, suggesting that the pituitary could have secreted substantial amounts of LH if other factors had been favourable. There was, therefore, an important characteristic of pituitary behaviour observed in this study, namely that the
Figure 8 The responsiveness of FSH secretion, to $\mathrm{GnRH}$, from hemipituitaries of female rats in vitro. The tissue was incubated in control medium and then in the presence of $1 \mathrm{nM} \mathrm{GnRH}$; the ratio of $\mathrm{GnRH}$-stimulated FSH release to basal FSH release was calculated. The pituitaries were collected from the rats at the times indicated on the day of pro-oestrus. The means and S.E.M. are depicted.

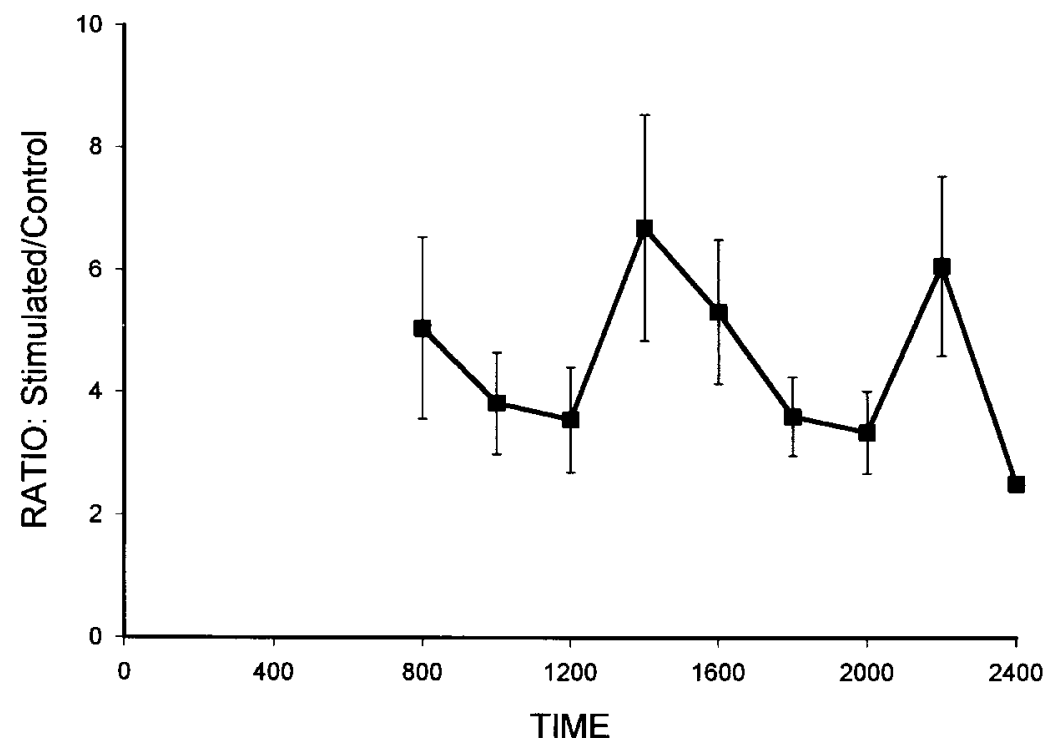


absolute amount of GnRH-induced LH secretion declined at a time when the responsiveness (ratio of stimulated/basal) was high. This suggests either that stores of LH had been depleted or alternatively, or additionally, that factors other than GnRH were modulating the response to the primary secretagogue.

Changes in responsiveness of altered endocrinological environments have also been noted by other authors. In considering the full oestrous cycle, a change in $\mathrm{LH}$ responsiveness to GnRH from pro-oestrus to other stages of the cycle has been observed $(16-18,37)$. Our study considered in detail the day of pro-oestrus. Results were obtained that were at variance in some aspects with results obtained by others from in vivo studies. When studying the effect of administration of GnRH, it was observed that the ratio of postinjection levels of LH to preinjection levels (responsiveness) was actually less between $1600 \mathrm{~h}$ and $2100 \mathrm{~h}$ than earlier between $1000 \mathrm{~h}$ and $1500 \mathrm{~h}$ (19). Thus, in those in vivo studies, there was no increase in responsiveness during the time leading up to the LH surge. During extended incubations, the response in vitro to GnRH initially increased but later declined in pituitaries taken between $1000 \mathrm{~h}$ and $1800 \mathrm{~h} \mathrm{(38).} \mathrm{However,} \mathrm{no} \mathrm{tissue} \mathrm{was} \mathrm{taken}$ for study at times following the LH surge on pro-oestrus. There is indeed a paucity of experimental data on in vitro characteristics during the declining phase of the $\mathrm{LH}$ surge and in the presence of the correspondingly elevated levels of FSH. This is a time when the regulation of the two gonadotrophins has a clearly distinct component.

This present study was also designed to obtain data during the declining phase of the LH surge in contrast to most previous investigations. One possible component of the decline of the $\mathrm{LH}$ surge might be a lowered responsiveness to GnRH even in the continued presence of the secretagogue. In an investigation of the interval between the mornings of pro-oestrus and oestrus it seemed that lowered output of LH could be due to desensitisation (39) after the middle of the dark phase at the end of pro-oestrus, i.e. well after the LH decline. That our results did not detect desensitisation (i.e. reduced responsiveness) might be partly due to the chosen protocol. The incubation time was deliberately kept relatively short so that complications due to desensitisation might be reduced. In addition, pituitary pieces were employed which are likely to retain paracrine-regulated processes. Other authors, using in vivo protocols, have suggested that refractoriness plays only a minor role in the decline of the LH surge (40).

The results indicated that the basal levels secreted in vitro, in the absence of added GnRH, seem to be an important index of the amount of LH which is secreted in vivo, because responsiveness was not parallel to the serum profile. Our results point to an increase in responsiveness during the decline of the LH surge. The reduction in peripheral serum LH levels presumably implies that a reduction of GnRH-stimulated secretion occurs. Thus, lower basal LH secretory activity (as observed after the LH peak), even accompanied by high responsiveness, is an impediment to high in vivo levels. There is some debate over the profile of GnRH during the declining phase of the LH surge, some noting an early decline after peak levels are reached (26), whereas others have observed a plateau of retained high GnRH levels (27). However, whatever the levels of $\mathrm{GnRH}$ which are delivered via the portal blood system to the pituitary, the control of basal secretory levels by the modulatory processes in vivo is apparently an important component of the regulation of the gonadotrophin serum profile. The ratio of mean LH serum level at $1800 \mathrm{~h}$ to that at $2400 \mathrm{~h}$ is bigger than the ratio of basal secretion levels, and also of in vitro GnRH-stimulated levels, at the same times (i.e. $1800 \mathrm{~h}$ and $2400 \mathrm{~h}$ ). This also suggests that further factors, other than GnRH, are involved in determining serum concentrations; otherwise a tight relationship between these secretory parameters would be observed.

Alternatively or in addition to the effects detected in vitro, in vivo there might be other modulating factors which act at the pituitary level to reduce the stimulatory effectiveness of GnRH. Such factors can include desensitisation by endothelin (41), or inhibition by opioids acting on the pituitary $(42,43)$ or by substance $\mathrm{P}(44)$.

A different picture emerged from consideration of FSH profiles. The role of GnRH in the generation of FSH profiles has been debated for some time. The rise in serum FSH at the same time as that of LH is consistent with $\mathrm{GnRH}$ being primarily responsible for the first phase of the FSH rise $(27,45,46)$. At the end of prooestrus, however, serum FSH was still raised, as previously observed in several studies (1-3), and in contrast to the fall in LH. Thus, the raised levels occurred in the apparent absence of raised GnRH levels (26). However, the second, late pro-oestrus increase of FSH does not take place as a result of an increase in responsiveness to GnRH. There were no alterations in responsiveness parallel to the changes in secretion during the day of pro-oestrus. There was a wide fluctuation of responsiveness of FSH to GnRH, implying that the responsiveness of FSH is less tightly associated in individual rats with time of day or basal level of hormone than responsiveness of LH. These results, therefore, provide further evidence for control of basal and of GnRH-stimulated FSH release via separate mechanisms. That there is a GnRH-independent component to $\mathrm{FSH}$ regulation, possibly involving activin and progesterone receptor, is established $(47,48)$. Modulation of gonadotrophin storage is also possible. In vitro, there was increased secretion, in the absence of added secretagogues, from pituitaries taken at the end of prooestrus. The results agree with those obtained by others who observed a similar pattern (35). A good relationship between serum FSH levels and basal secretion has been previously reported (36). 
The variation in basal secretion, of both LH and FSH, from the pituitary over the day of pro-oestrus is observed some hours after the pituitary has been removed from the in vivo influences. Thus, the differences reflect longlasting components of the regulatory mechanism, resulting in a peak of basal in vitro secretion from tissue taken at a time coincident with the in vivo peak. Of some interest in this regard is the suggestion that the duration of the effect of GnRH and other factors might extend beyond the time of their actual presence at the pituitary (49). Contributions from long-term activation of processes involving intrapituitary peptides might also be present (6).

In summary, with respect to the control of gonadotrophs, during the day of pro-oestrus, the amounts of LH and FSH which are induced by GnRH are dependent only partly on the responsiveness of cells to this secretagogue. There may be negative modulation to keep releasable stores low in late pro-oestrus or involvement of other factors which can contribute to the regulatory system in vivo $(6,9,12)$. This current study reports on the direct relationship between measured peripheral levels and in vitro secretion from the pituitary source, and concludes that, even when isolated from the acute effect of the hypothalamus, the pituitary exhibits regulated activities. This implies that the temporal profile of modulating hypothalamic factors in vivo must take account of both the longevity of effect and also the residual effects of earlier controls.

\section{Acknowledgements}

We are very grateful to NIDDK's National Hormone Pituitary Program and Dr A F Parlow for the generous gift of immunochemicals and to Professor S R Bloom for support during this study.

\section{References}

1 Gay VL, Midgley AR \& Niswender GD. Patterns of gonadotrophin secretion associated with ovulation. Federation Proceedings 1970 29 1880-1887.

2 Butcher RL, Collins WE \& Fugo NW. Plasma concentration of LH, FSH, prolactin, progesterone and estradiol 17beta throughout the 4-day estrous cycle of the rat. Endocrinology $1974941704-$ 1708.

3 Smith MS, Freeman ME \& Neill JD. The control of progesterone secretion during the estrous cycle and early pseudopregnancy in the rat: prolactin, gonadotropin and steroid levels associated with rescue of the corpus luteum of pseudopregnancy. Endocrinology $197596219-226$

4 Conn PM, Janovick JA, Stanislaus D, Kuphal D \& Jennes L. Molecular and cellular basis of gonadotropin-releasing hormone action in the pituitary and central nervous system. Vitamins and Hormones $199550151-214$.

5 Stojilkovic SS \& Catt KJ. Novel aspects of GnRH-induced intracellular signaling and secretion in pituitary gonadotrophs. Journal of Neuroendocrinology 19957 739-757.

6 Evans JJ. Modulation of gonadotropin levels by peptides acting at the anterior pituitary gland. Endocrine Reviews $19992046-$ 67.
7 Fink G. Oestrogen and progesterone interactions in the control of gonadotrophin and prolactin secretion. Journal of Steroid Biochemistry $198830169-178$.

8 Turgeon JL \& Waring DW. Rapid augmentation by progesterone of agonist-stimulated luteinizing hormone secretion by cultured pituitary cells. Endocrinology 1990127 773-780.

9 Ortmann O, Bakhit M, Bloh P, Schulz KD \& Emons G. Ovarian steroids modulate gonadotropin-releasing hormone-induced biphasic luteinizing hormone secretory responses and inositol phosphate accumulation in rat anterior pituitary cells and alpha T3-1 gonadotrophs. Journal of Steroid Biochemistry and Molecular Biology 199554 101-109.

10 Halvorson LM \& DeCherney AH. Inhibin, activin, and follistatin in reproductive medicine. Fertility and Sterility 199665 459469.

11 DePaolo LV. Inhibins, activins, and follistatins: the saga continues. Proceedings of the Society for Experimental Biology and Medicine $1997214328-339$.

12 Mather JP, Moore A \& Li RH. Activins, inhibins, and follistatins: further thoughts on a growing family of regulators. Proceedings of the Society for Experimental Biology and Medicine 1997215 209222.

13 Stojilkovic SS, Rojas E, Stutzins A, Izumi S \& Catt, KJ. Desensitization of pituitary gonadotropin secretion by agonistinduced inactivation of voltage-sensitive calcium channels. Journal of Biological Chemistry 1989264 10939-10942.

14 Hawes BE, Marzen JE, Waters SB \& Conn PM. Sodium fluoride provokes gonadotrope desensitization to gonadotropin-releasing hormone $(\mathrm{GnRH})$ and gonadotrope sensitization to A23187: evidence for multiple $\mathrm{G}$ proteins in GnRH action. Endocrinology $19921302465-2475$.

15 McArdle CA, Willars GB, Fowkes RC, Nahorski SR, Davidson JS \& Forrest-Owen W. Desensitization of gonadotropin-releasing hormone action in $\alpha \mathrm{T} 3-1$ cells due to uncoupling of inositol 1,4,5triphosphate generation and $\mathrm{Ca}^{2+}$ mobilization. Journal of Biological Chemistry $199627123711-23717$.

16 Cooper KJ, Fawcett CP \& McCann SM. Variations in pituitary responsiveness to a luteinizing hormone/follicle stimulating hormone releasing factor (LH-RF-FSH-RF) preparation during the rat estrous cycle. Endocrinology 197495 1293-1299.

17 Legan SJ \& Karsch FJ. Modulation of pituitary responsiveness to luteinizing hormone-releasing factor during the estrous cycle of the rat. Endocrinology 197596 571-575.

18 Zeballos G \& McCann SM. Alterations during the estrous cycle in the responsiveness of the pituitary to subcutaneous administration of synthetic LH-releasing hormone (LHRH). Endocrinology $1975961377-1385$.

19 Aiyer MS, Fink G \& Greig F. Changes in the sensitivity of the pituitary gland to luteinizing hormone releasing factor during the oestrous cycle of the rat. Journal of Endocrinology $19746047-64$.

20 Gordon JH \& Reichlin S. Changes in pituitary responsiveness to luteinizing hormone-releasing factor during the rat estrous cycle. Endocrinology $197494974-978$.

21 Thomson FJ, Johnson MS, Mitchell R \& Wolbers B. Evidence for a role of phospholipase A2 in the mechanism of LHRH priming in rat anterior pituitary tissue. Journal of Endocrinology 1994141 $15-31$.

22 Evans JJ, Hurd SJ \& Mason DR. Oxytocin modulates the luteinizing hormone response of the rat anterior pituitary to gonadotrophinreleasing hormone. Journal of Endocrinology 1995145 113-119.

23 Hall JE, Brodie TD, Badger TM, Rivier J, Vale W \& Conn PM. Evidence of differential control of FSH and $\mathrm{LH}$ secretion by gonadotropin-releasing hormone (GnRH) from the use of a GnRH antagonist. Journal of Clinical Endocrinology and Metabolism 1988 $67524-531$.

24 Kile JP \& Nett TM. Differential secretion of follicle-stimulating hormone and luteinizing hormone from ovine pituitary cells following activation of protein kinase $\mathrm{A}$, protein kinase $\mathrm{C}$, or increased intracellular calcium. Biology of Reproduction 199450 49-54. 
25 Tsujii T \& Winters SJ. Effects of pulsatile pituitary adenylate cyclase activating polypeptide (PACAP) on gonadotropin secretion and subunit mRNA levels in perifused rat pituitary cells. Life Sciences 199556 1103-1111.

26 Sarkar DK, Chiappa SA, Fink G \& Sherwood NM. Gonadotropinreleasing hormone surge in pro-oestrous rats. Nature 1976264 461-463.

27 Ching M. Correlative surges of LHRH, LH and FSH in pituitary stalk plasma and systemic plasma of rat during proestrus. Neuroendocrinology $198234279-285$.

28 Levine JE. New concepts of the neuroendocrine regulation of gonadotropin surges in rats. Biology of Reproduction 199756 293-302.

29 Speight A \& Fink G. Changes in responsiveness of dispersed pituitary cells to luteinizing hormone releasing hormone at different times of the oestrous cycle of the rat. Journal of Endocrinology 198189 129-134.

30 Waring DW \& Turgeon JL. A pathway for luteinizing hormone releasing-hormone self-potentiation: cross-talk with the progesterone receptor. Endocrinology 1992130 3275-3282.

31 Mitchell R, Sim P, Leslie T, Johnson MS \& Thomson FJ. Activation of MAP kinase associated with the priming effect of LHRH. Journal of Endocrinology 1994140 R15-R18.

32 Evans JJ \& Tulloch S. Effects of administration of oxytocin in association with gonadotrophin-releasing hormone on luteinizing hormone levels in rats in vivo. Peptides 199516 145-150.

33 Crowley WR, Shah GV, Carroll BL, Kennedy D, Dockter ME \& Kalra SP. Neuropeptide-Y enhances luteinizing hormone (LH) releasing hormone-induced LH release and elevations in cytosolic $\mathrm{Ca}^{2+}$ in rat anterior pituitary cells: evidence for involvement of extracellular $\mathrm{Ca}^{2+}$ influx through voltage-sensitive channels. Endocrinology 1990127 1487-1494.

34 Bauer-Dantoin AC, Knox KL, Schwartz NB \& Levine JE. Estrous cycle stage-dependent effects of neuropeptide-Y on luteinizing hormone (LH)-releasing hormone-stimulated LH and folliclestimulating hormone secretion from anterior pituitary fragments in vitro. Endocrinology 1993133 2413-2417.

35 Elias KA \& Blake CA. A detailed in vitro characterization of the basal follicle-stimulating hormone and luteinizing hormone secretion rates during the rat four-day estrous cycle. Endocrinology $1981109708-713$.

36 Elias KA, Kelch RP, Lipner H \& Blake CA. Relationship between basal gonadotropin secretion rates and serum gonadotropin concentrations in proestrous rats. Biology of Reproduction 1982 27 1159-1168.

37 Aiyer M, Chiappa SA \& Fink G. A priming effect of luteinizing hormone releasing factor on the anterior pituitary gland in the female rat. Journal of Endocrinology 197462 573-588.

38 Ferland L, Borgeat P, Labrie F, Bernard J, De Lean A \& Raynaud J-P. Changes of pituitary sensitivity to LH-RH during the rat estrous cycle. Molecular and Cellular Endocrinology 19752 107-115.
39 Cassina MP \& Neill JD. Gonadotropin-releasing hormone-induced desensitization may account for the decrease in pituitary responsiveness after the preovulatory luteinizing hormone surge. Endocrinology 1996137 1057-1062.

40 Blake CA \& Garner LL. Pituitary refractoriness to luteinizing hormone releasing hormone: its importance in ending the luteinizing hormone surge in the cyclic rat. Proceedings of the Society for Experimental Biology and Medicine 1980164 374379.

41 Stojilkovic SS, Iida T, Cesnjaj M \& Catt KJ. Differential actions of endothelin and gonadotropin-releasing hormone in pituitary gonadotropes. Endocrinology 1992131 2821-2828.

42 Dragatsis I, Papazafiri P, Zioudrou C \& Gerozissis K. Opioids modify the release of LH at the pituitary level: in vitro studies with entire rat pituitaries. Journal of Endocrinology 1995145 263270.

43 Kandeel FR \& Swerdloff RS. The interaction between B-endorphin and gonadal steroids in regulation of luteinizing hormone (LH) secretion and sex steroid regulation of LH and proopiomelanocortin peptide secretion by individual pituitary cells. Endocrinology $1997138649-656$.

44 Duval P, Lenoir V, Garret C \& Kerdelhue B. Reduction of the amplitude of preovulatory LH and FSH surges and of the amplitude of the in vitro GnRH-induced LH release by substance P. Reversal of the effect by RP67580. Neuropharmacology 199635 1805-1810.

45 Sanchez-Criado JE, Hernandez G, Bellido C, Gonzalez D, Tebar M, Diaz-Cruz MA \& Alonso R. Periovulatory LHRH, LH and FSH secretion in cyclic rats treated with RU486: effects of exogenous LHRH and LHRH antagonist on LH and FSH secretion at early oestrus. Journal of Endocrinology 1994141 7-14.

46 Rush ME, Ashiru O \& Blake CA. Hypothalamic-pituitary interactions during the periovulatory secretion of follicle-stimulating hormone in the rat. Endocrinology 1980107 649-655.

47 Farnworth PG. Gonadotrophin secretion revisited. How many ways can FSH leave a gonadotroph? Journal of Endocrinology 1995 $145387-395$.

48 Szabo M, Knox KL, Ringstrom SJ, Perlyn CA, Sutandi S \& Schwartz NB. Mechanism of the inhibitory action of RU486 on the secondary follicle-stimulating hormone surge. Endocrinology $199613785-89$.

49 Fallest PC \& Schwartz NB. Pituitary luteinizing hormone (LH) and follicle-stimulating hormone (FSH) responses to gonadotropinreleasing hormone during the rat estrous cycle: an increased ratio of FSH to LH is secreted during the secondary FSH surge. Biology of Reproduction 199043 977-985.

Received 19 March 1999

Accepted 9 July 1999 